\title{
Aspects that could be Enhanced during the Initial and Continuous Training of the Primary School Teachers from Romania
}

Nicoleta-Eugenia Meseșan, Diana-Crina Marin 


\title{
Aspects that could be Enhanced during the Initial and Continuous Training of the Primary School Teachers from Romania
}

\author{
Nicoleta-Eugenia Meseșan ${ }^{a *}$, Diana-Crina Marin ${ }^{b}$ \\ ${ }^{a, b}$ Doctoral School "Education, Reflection, Development”, Babes-Bolyai University Cluj-Napoca, 7 Sindicatelor Street, 400029, Romania \\ *Corresponding author: nicoletamese@yahoo.com
}

\section{Abstract}

Keywords:

professional competencies of the teachers; initial and continuous training; educational partnership; efficient strategies; beginner teachers.
Effective cooperation between parents and teachers has a huge effect on children's harmonious development. This study was conducted in order to establish the interests and the training needs of the teachers who are at the beginning of their careers. Recent studies have shown that children's positive school performances are strongly related to a high degree of family involvement in their education. The study has revealed that at the beginning of their teaching career some teachers felt vulnerable in the relationship with the parents. Also, some of them have lived negative experiences in the process of building an authentic partnership between the school and the families. The study has revealed that more attention should be given to pedagogical practice by creating contexts through which the future teachers organize and assist at activities with the parents. At the same time, the legislative framework regarding the activities of the mentors should be improved.

\section{Zusammenfasung}

\section{Schlüsselworte:}

Berufliche Kompetenzen der Lehrer; Aus- und Weiterbildung; Bildungspartnerschaft; effiziente Strategien; angehende Lehrer.
Eine effektive Zusammenarbeit zwischen Eltern und Lehrern hat einen großen Einfluss auf die harmonische Entwicklung der Kinder. Diese Studie wurde durchgeführt, um die Interessen und den Ausbildungsbedarf der Lehrer, die am Anfang ihrer Karriere sind, zu ermitteln. Aktuelle Studien haben gezeigt, dass die positiven schulischen Leistungen von Kindern stark mit einem hohen Maß an Familienbeteiligung in ihrer Erziehung zusammenhängen. Die Studie hat ergeben, dass sich einige Lehrer zu Beginn ihrer Lehrerkarriere in der Beziehung zu den Eltern verletzlich fühlten. Außerdem haben einige von ihnen negative Erfahrungen im Prozess des Aufbaus einer authentischen Partnerschaft zwischen der Schule und den Familien gemacht. Die Studie hat gezeigt, dass der pädagogischen Praxis mehr Aufmerksamkeit gewidmet werden sollte, durch die Einführung von Situationen, durch die die zukünftigen LehrerInnen Aktivitäten mit den Eltern organisieren und unterstützen. Gleichzeitig sollte der gesetzliche Rahmen bezüglich der Aktivitäten der Mentoren verbessert werden.

\section{Introduction}

Recent research studies have revealed that the didactic approaches through which each child is valued and systematically encouraged and studentcentered pedagogical practices are current trends with positive effects on pupils' school results and on the process of building effective partnerships between the school and the family. We believe that all persons who teach in primary education must know viable strategies to increase parental involvement in children's education and effective modalities to cooperate with parents. Generally, the abilities of communication, the level of their didactic competencies, empathy, and other personal qualities of teachers are associated with effective relationships with parents and other educational partners. We believe that the involvement of parents is an important way to support the academic achievement of students.
Positive relationships between parents and teachers are recognized as vital in this process of encouraging the student in order to obtain positive performances in the learning processes (Minke, et al, 2014).

\section{Theoretical foundation}

The degree of family involvement in children's education influences the level of pupils' motivation for learning, pupils' school results, and the degree of development of their multiple intelligences (Fantuzzo, McWayne, Perry, \& Childs, 2004; Fishel \& Ramirez, 2005; Izzo, Weissberg, Kasprow, \& Fendrich, 1999; Pavalache-Ilie \& Țîrdia, 2015).

The study conducted by Marin \& Bocos (2018) revealed that effective cooperation between school and families in order to optimize the learning of students in the family space is beneficial and contributes to the 
process of development of the children's multiple intelligences.

Also, the same study has revealed that the system used for evaluating the activity of teachers should also cover several aspects regarding the quality of cooperation between school and family (Marin \& Bocoș, 2018). Another study conducted in 2019 revealed that, in the opinion of school principals, the results of recent research on the process of strengthening the school-family partnership should be frequently disseminated and discussed by teachers during their meetings. Also, school principals are aware of the importance of building an effective partnership between school and family, agreeing that a high involvement of the family in school life has positive effects on the cooperation between parents and teachers. Recent studies have shown that organizing educational workshops for parents and students and extracurricular activities could positively influence the quality of the cooperation between parents and students (Marin \& Bocoș, 2018; Marin \& Bocos, 2019).

The document "Building Federation of ParentTeacher Relationships" (2007) of the American Federation of Teachers, mentions that effective communication between school and parents is necessary and beneficial for all educational partners. Thus, parents:

- are informed about the learning strategies used during the school program,

- are receiving information about the pupils' performances, their school results and also about their son/daughter's learning needs,

- are feeling involved in their own children's education.

At the same time, teachers:

- are receiving information about children's learning at home;

- can better support students in the learning activities;

- have a better opinion on the importance of the school activities and so the children's and the teachers' motivation increases;

For pupils, a positive influence is highlighted in:

- $\quad$ increasing the school results;

- $\quad$ increasing the motivation for learning;
- improving the student's behaviour;

- generating positive attitudes towards school tasks and school in general.

The process of building effective school-family partnerships could be affected by various challenges and obstacles that are not related to the teacher's activity. Recent studies revealed that regular meetings and communication between parents and teachers are positive practices that could prevent conflicts and the differences of visions (Marin \& Bocoș, 2019). According to the results of this study, some of the obstacles frequently encountered are the socioeconomic status of the family, the inadequate intervention of some parents in the educational process, a low level of confidence between partners, and the long absence of some of the parents who work in other countries.

\section{Research methodology}

The issue of the parent-school relationship is an essential topic, considering the positive influences of their continuous cooperation on the efficiency of the instructive-educational activity. Understanding the importance of the issue of school-family cooperation, we have decided to follow this aspect of the teaching activity by conducting a survey. The questionnaire created by us contains seven questions (see Annex 1). Five of the questions allow the selection of multiple variants of response, while two of them are openended questions. The questions were created to collect information about the teachers' experiences related to the relationships with parents. Also, recommendations for beginning teachers were formulated.

\section{Results}

The distribution of the respondents in the research group is the following: 50 teachers, with different teaching experience, who work in both urban and rural areas. Thus, the distribution of the group of respondents, considering their work seniority, is the following: between $0-2$ years ( $18 \%$ of the respondents, i.e. 9 people), $2-5$ years ( $16 \%$ of the respondents, i.e. 8 people), between $5-10$ years $(14 \%$ of the respondents, i.e. 7 people), and over 10 years (50\% of the respondents, i.e. 26 people). 
Figure 1. The description of the group of respondents, considering their work seniority

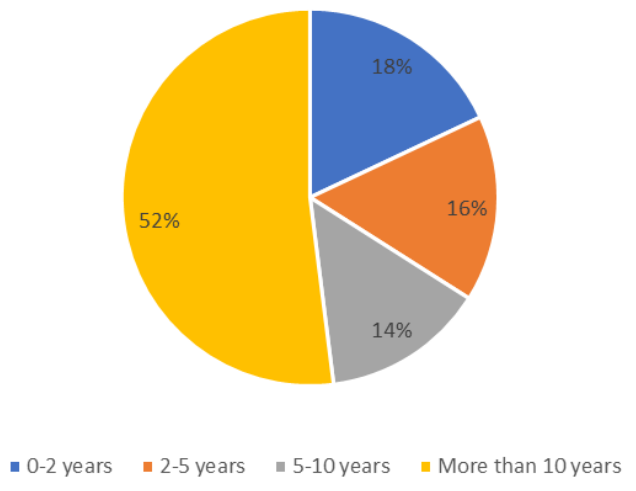

The teachers' group was composed of teachers with work seniority less than 10 years. They were selected considering that they have lived more recently the beginners' experiences so their needs are current and easily identifiable.

The questionnaire was applied in the online environment, using Google Docs applications, and for the quantitative interpretation of the data, the same application was used. The results will be presented below.

Thus, for the first question: "How was the first interaction with the parents of the students from your class, as a beginner?", $34 \%$ of the respondents (i.e. 17 teachers) stated that they felt very well, because they felt openness from on the parents' side, and 38\% (i.e. 24 teachers) among the respondents felt pleasant in their new role. This interaction was difficult and very difficult for $14 \%$ of teachers, and $1 \%$ do not remember (see Figure 2).

Figure 2. The perception of the teacher regarding the first interaction, as a beginner, with the parents

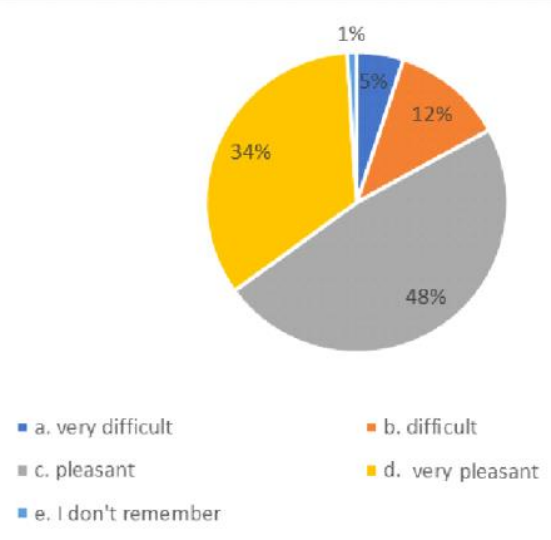

For the question "Do you consider that there were errors in your relationship with your parents?", $72 \%$ of the respondents (i.e. 36 teachers) considered that there were no errors, while and $28 \%$ of them (14 respondents) answered affirmatively (see Figure 3).

Figure 3. The opinions of the teachers regarding the possible errors that occurred during the process of constructing an effective partnership with parents

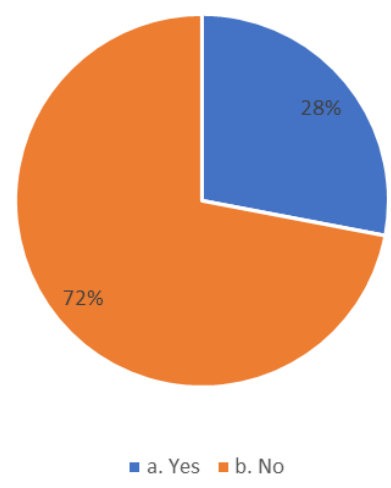

Through question no 3, we aimed to establish some difficult situations or mistakes that were made by the teacher in the relationship with the parents. Among the examples listed most often were: communication errors, lack of trust in a beginner, lack of feedback, lack of empathy from the teacher, too much distance or closeness in the relations with parents, difficulties in communicating with parents whose children had behavioural problems, lack of firmness on the part of the teacher.

Question 4 has the purpose to establish the efficiency of the initial training of the teachers; in the field of the school-family partnership. Most respondents ( $64 \%$ of the respondents, i.e. 36 teachers) stated that they were very well prepared or well prepared, but $26 \%$ of them were poorly prepared to interact with parents (i.e. 13 respondents). $6 \%$ of the respondents felt unprepared for their first interactions with the parents (3 teachers) (see Figure 5).

Figure 5. The opinions of the respondents regarding the efficiency of their initial training

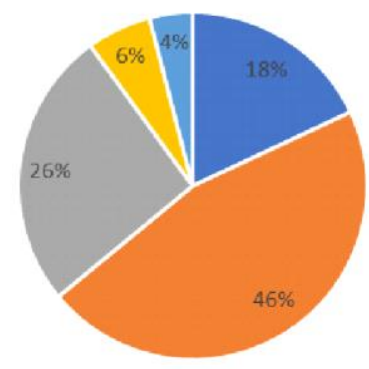

\footnotetext{
- a. very well prepared $\|$ b. relatively prepared $\|$ c. poorly prepared

॥ d. unprepared = e. Idon't remember
} 
The beginning teachers have received support from a colleague regarding the process of consolidating the partnership with the families, in 50\% of the respondents (i.e. 25 teachers). The mentor established by the school or the school management offered support for $10 \%$ of respondents (i.e. 5 teachers). $28 \%$ of the respondents, respectively 14 teachers, stated that they did not receive any help (see Figure 6).

Figure 6. Persons who offered assistance to the beginning teachers
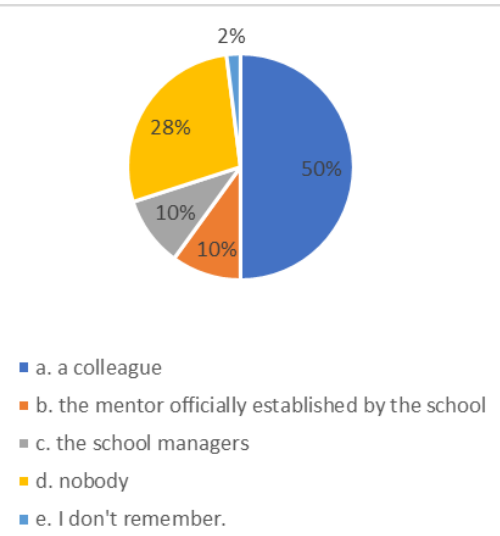

In order to increase the quality of training in the field of the optimal management of the relationships with parents, respondents have recommended that during the initial training future teachers should carry out various specific activities. Thus, the simulation of meetings/meetings with parents is the solution proposed by $70 \%$ of the respondents (i.e. 35 teachers), organizing practical activities, conducted in application schools, in collaboration with students' families are proposed by $58 \%$ of the respondents (29 persons), and more time specially allocated for theoretical training in the field of school-family partnership is the option proposed by $34 \%$ of the teachers who filled in the questionnaire, respectively 17 persons (see Figure 7).

Figure 7. Proposals for improving the initial training of future teachers

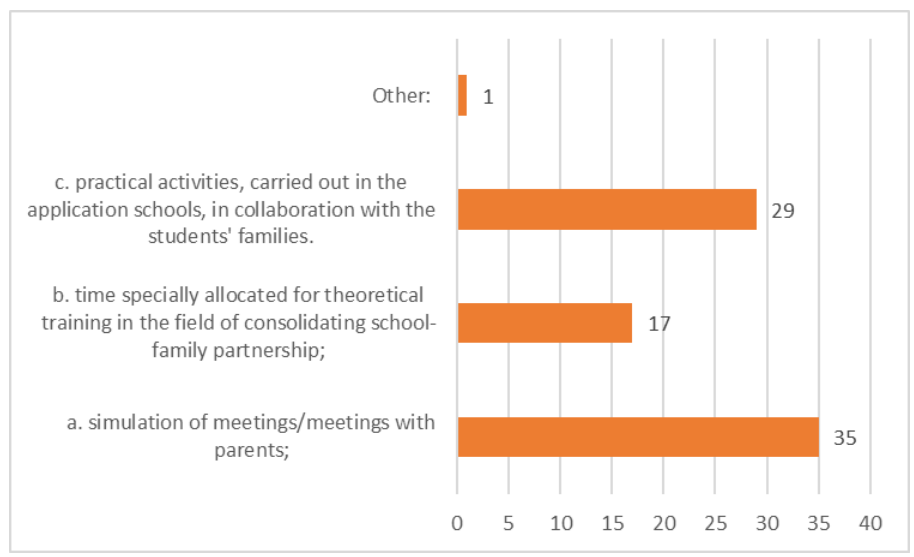

Through question no 7, respondents were asked to provide advice to beginning teachers in order to maintain a good relationship with the parents of their students. The advice offered was numerous and diverse. The respondents recommended: good professional training, assertive communication, the manifestation of empathy, calm tone, respect for parents, self-confidence, but without irony and superiority, and active listening. Some of the recommendations were related to a permanent collaboration with more experienced colleagues, but also with the school manager, who can be a good mentor, being able to support the beginning teacher in building an effective collaboration and communication relationship with each parent.

By analysing the obtained results, we can affirm that most of the respondents considered that it was easy to establish a collaborative relationship with the parents, and their attributions were facilitated even by the parents, in some cases. In general, the beginning of their career was pleasant, enjoyable, interesting. Only a small part of the respondents encountered difficulties in collaborating with the students' families, which is not surprising because the multitude of tasks assigned to a beginner teacher can be overwhelming, and establishing relationships with people of different ages, roles and functions can generate a constant pressure. It is gratifying that in most cases, parents have facilitated the school-family collaboration, offering support, respect, and trust to the teacher.

It is also noteworthy that very few respondents say that they made mistakes in the relationship with the parents of their students. This attitude can be generated both by the high level of the quality of the initial training and by the support offered by colleagues, mentors, or school management for a correct and efficient start in this field of the teacher's activity.

According to the answers offered by the respondents, the support offered to beginners in the field of school collaboration with the family, was generally provided by colleagues. Mentors from the school or from other schools, in exceptional situations, are the ones who should take care of the beginner's activity in all areas of activity, including the relationship with the pupils' families. But, after analysing the collected answers, mentors were mentioned by only $10 \%$ of the respondents, as resource persons for beginning teachers. One argument could be that the mentoring activity is not well defined in the actual legislative framework, 
which creates deficiencies in their activity. Another argument would be that a novice teacher may more easily establish professional relationships with a colleague that he feels closer to, and not with an officially designated person.

\section{Discussions}

According to the respondents' responses, some of the beginning teachers have not received sufficient support in this area of their activity. This fact is worrying and could lead to difficult situations, generating anxiety or even conflictual relationships with parents. We believe that both the mentor and the schools' managers should help the beginning teachers, in order to have an efficient and coherent activity, not only to offer them support when conflictual situations occur. We believe that a coherent approach and adequate guidance will prevent the number of conflict situations or of dysfunctional relationships between the teachers and the students' families. Of course, this would increase the beginner teacher's self-confidence and could give credibility to his actions from the parent's perspective.

The main limit of this investigation is related to the short number of participants. Collaboration with parents is an important area of the activity of each teacher. We consider that the professional development of teachers in the direction of family counselling is important and beneficial. A high degree of empathy, positive attitudes toward parents and towards the teachers' activity and usually sending encouraging messages for parents and students should decrease the occurrence of conflictual situations and defensive attitudes of educational partners. If teachers and the school staff adopt frequently welcoming and friendly attitudes, the school environment will become more attractive and accessible for parents.

\section{Conclusions}

In conclusion, this present research highlights some important aspects regarding the activity of the primary school teachers:

- collaboration with students' families is an important segment of the teaching activity;

- the abilities to manage in an effective way school-family relationship are very important for all teachers;

- it is necessary to identify optimal strategies to enhance the involvement and the collaboration of the school with the family;
- the training of teachers for collaboration with students' families must be done both in the initial training stage and in later stages;

- the beginning teacher must show an increased interest in developing this dimension of professional competence, but must also to benefit from the support and guidance from both mentors and the school management.

The fact that many of the respondents did not receive support and did not make mistakes in the process of building the school-family partnership, leads us to the idea of very good training in this field in the initial training stage. Even if they did not have negative experiences in this field, all the respondents believed that more attention should be given to the strategies used in the initial training of the teachers. We can conclude that during the initial training of the teachers more attention should be given to the practical approaches to this field, not only to the theoretical information. During the stage of pedagogical practice, the teachers-mentors should create opportunities for beginning teachers to interact with the parents. In this way, the competencies which are necessary for this sector of their didactic activity will be formed from a practical perspective, not just from a theoretical approach. We consider the organization of simulations of meetings with parents or even the participation in meetings organized with parents of the students to be very useful. At the same time, we are aware that, unfortunately, the future teachers' involvement in the activities with the parents is not always accepted or encouraged and the future teachers are extremely rarely involved in this type of activity. The reasons can be various, such as the possible restraints imposed by the parents regarding the participation of an unknown person during the activities, the insecurity of the teacher in the relationship with the parents, the legislative framework regarding the protection of students' data, etc.

\section{Acknowledgments}

We would like to thank all the participants for their support in conducting this study.

Authors note: The authors have equal contributions to this article.

Nicoleta-Eugenia Meseșan is currently a pedagogy teacher at "Gheorghe Lazăr" Pedagogical National College, in Cluj-Napoca and a collaborator of Babeș-Bolyai University. She is a researcher interested in finding the best strategies that could be 
used in order to optimize the initial and continuous training of teachers. In 2020, she obtained a Ph.D. in Educational Sciences, from the Babeș-Bolyai University.

Diana-Crina Marin is currently a teacher at "Pavel Dan" Theoretical High School, in Câmpia Turzii and a postdoctoral researcher at the BabeșBolyai University. Her research areas are aimed to find innovative modalities to consolidate the school-family partnership, considering that the school and family should be real partners regarding the children's education. She is also interested in finding the most effective teaching practices that could be successfully used in the educational process.

\section{Appendix A.}

\section{Questionnaire regarding the teacher-parent relationship}

\section{Dear Colleagues,}

The questionnaire below was designed in order to establish the training needs of the teachers in the field of consolidating the school-family partnership. By answering these questions, you will help us to identify some problems and will propose optimal solutions together. Thank you for your availability!

1. How was the first interaction, as a beginner, with the parents of the students from your class?

a. very difficult

b. difficult

c. pleasant

d. very pleasant, because felt parents' openness and their availability to cooperate

e. I don't remember

2. Do you consider that there were errors in your relationship with the parents?
a. Yes
b. No

3. If you answered "Yes" to the above question, give 1-2 examples.

4. Did you feel ready at the beginning of your career to interact with the parents of your students?

a. very well prepared

b. relatively prepared
c. poorly prepared
d. unprepared
e. I don't remember

5. In your relationship with the parents, you have received support from:

a. a colleague

b. the mentor officially established by the school

c. the school managers

d. nobody

e. I don't remember.

6. In order to optimize the training of the future teachers in the field of school-family partnership, the following should be organized during the initial training:

a. simulation of meetings/meetings with parents;

b. time specially allocated for theoretical training in the field of consolidating school-family partnership;

c. practical activities, carried out in the application schools, in collaboration with the students' families.

Other:

7. Write down some recommendations for teachers at the beginning of their career regarding the relationship with parents.

8. Seniority as a teacher:

a. 0 -2 years

b. 2-5 years

c. 5-10 years

d. In 10 years

Thank you for your time!

\section{References}

American Federation of Teachers, (2007). Building ParentTeacher Relationships. Washington, D.C.: American Federation of Teachers.

Fantuzzo, J., McWayne, C., Perry, M. A., \& Childs, S. (2004). Multiple dimensions of family involvement and their relations to behavioral and learning competencies for urban, low-income children. School Psychology Review, 33(4), 467-480. doi: https://doi.org/10.1080/02796015.2004.12086262

Fishel, M., \& Ramirez, L. (2005). Evidence-based parent involvement interventions with school-aged children. 
School Psychology Quarterly, 20, 371-402. doi: https://doi.org/10.1521/scpq.2005.20.4.371

Izzo, C. V., Weissberg, R. P., Kasprow, W. J., \& Fendrich, M. (1999). A longitudinal assessment of teacher perceptions of parental involvement in children's education and school performance. American Journal of Community Psychology, 27, 817-839. doi: 10.1023/a:1022262625984. PMID: 10723536

Marin, D.-C., \& Bocoș, M. (2018, in press). The Effects of a High Family Involvement in Pupils' Education. Manuscript submitted for publication.

Marin, D.-C., \& Bocoș, M. (2019). School Principals' Opinion on the Strategies of Strengthening SchoolFamily Partnership, The European Proceedings of
Social \& Behavioural Sciences EpSBS, LXIII, 544-550. doi: https://doi.org/10.15405/epsbs.2019.06.64.

Minke, K. M., Sheridan, S. M., Kim, E. M., Ryoo, Ji H., \& Koziol, N. A. (2014). Congruence In Parent-Teacher Relationships, Faculty Publications from CYFS. The Elementary School Journal. 114(4), 526-546. Retrieved from:

https://digitalcommons.unl.edu/cgi/viewcontent.cgi?art icle $=1098 \&$ context $=$ cyfsfacpub

Pavalache-Ilie, M., \& Țîrdia, F.-A. (2015). Parental Involvement and Intrinsic Motivation with Primary School Students. Procedia - Social and Behavioral Sciences, $\quad$ 187, 607-612. doi: https://doi.org/10.1016/j.sbspro.2015.03.113 